had non-extensive involvement (ACA: 2, ATA: 7, "other ANAs": 6) performing Goh et al score with the FVC correction. Extensive ILD was found among 18 patients (ACA: 4, ATA: 11, "other ANAs": 3). Despite the fact that ATA+ group was more likely to have an extensive involvement no statistical significance was met. About pulmonary function tests (PFT) the mean FVC was $98,45 \%$ on ACA group, whereas on ATA and other ANAs groups the mean FVC were $88,97 \%$ and $81,43 \%$ respectively. Statistical differences were found between first and third group, However this difference was not found when only patients with pulmonary involvement were analyzed.

Conclusion: In our cohort, ATA and other ANAs groups were more likely to develop pulmonary interstitial disease and to need inmunosuppressant treatment. Although the prevalence of ILD among ACA+ was only $10 \%$, $50 \%$ of them required, due to the functional impairment or extension, inmunosuppressant treatment. In spite of the low ILD-ACA+ incidence this complication should be kept in mind and periodical screening and assessment must be carried out as in other autoantibodies profiles.

Disclosure of Interests: None declared

DOI: 10.1136/annrheumdis-2019-eular.1650

Table 1. ACA ATA Other ANA[1]

\begin{tabular}{|c|c|c|c|}
\hline \multirow[b]{2}{*}{ Table 1} & \\
\hline & ACA & ATA & Other ANA \\
\hline Patients, n (\%) & $60(55,6)$ & $22(20,4)$ & $26(24,1)$ \\
\hline $\begin{array}{c}\text { Sex } \\
\text { Female }(\%) \\
\text { Male }(\%)\end{array}$ & $\begin{array}{c}57(95) \\
3(5)\end{array}$ & $\begin{array}{c}18(81,8) \\
4(18,2)\end{array}$ & $\begin{array}{l}21(80,8) \\
5(19,2)\end{array}$ \\
\hline Age at diagnosis, median (years) & 59 & 55 & 61,5 \\
\hline $\begin{array}{c}\text { Smoke } \\
\text { Active (\%) } \\
\text { Former (\%) }\end{array}$ & $\begin{array}{l}1,7 \\
23,3\end{array}$ & $\begin{array}{l}4,5 \\
4,5\end{array}$ & $\begin{array}{l}11,5 \\
26,9\end{array}$ \\
\hline $\begin{array}{l}\text { DIAGNOSIS } \\
\text { IcSSc (\%) } \\
\text { dcSSc (\%) }\end{array}$ & $\begin{array}{c}55(91,7) \\
4(6,7)\end{array}$ & $\begin{array}{c}4(18,2) \\
17(77,3)\end{array}$ & $\begin{array}{l}11(42,3) \\
11(42,3)\end{array}$ \\
\hline $\begin{array}{l}\text { Time from diagnosis to ILD, } \\
\text { mean (months) }\end{array}$ & 6 & 5 & 0 \\
\hline Death,n (\%) & $8(57,2)$ & $2(14,2)$ & $4(28,6)$ \\
\hline PCR, mean (DS) & $4,69(3,9)$ & $5,25(3,75)$ & $8,08(8,34)$ \\
\hline vSG. median (mm/h) & 18 & 20.5 & 21 \\
\hline $\mathrm{PH}(\%)$ & 23.7 & 18.2 & 19.2 \\
\hline GERD (\%) & 72,9 & 77,3 & 57,7 \\
\hline ILD, n (\%) & $6(10)$ & $18(81,8)$ & $9(34,6)$ \\
\hline FVC, mean (DS) & $98,4(18,5)$ & $88,9(21,7)$ & $81,42(22,8)$ \\
\hline DLCO, mean (DS) & $72,5(20,4)$ & $75,5(35,9)$ & $73,4(20,7)$ \\
\hline
\end{tabular}

\section{FRI0323 EVALUATION OF LIPID PROFILE AND ATHEROSCLEROSIS IN TREATMENT-NAÏVE PATIENTS DIAGNOSED WITH UNDIFFERENTIATED CONNECTIVE TISSUE DISEASE (UCTD)}

Giorgos Papamichail ${ }^{1}$, Athanasios Georgiadis ${ }^{2}$, Theodora Markatseli ${ }^{2}$ Charalampos Milionis ${ }^{1}$, Alexandros Drosos ${ }^{2}$, Paraskevi Voulgari ${ }^{2} .{ }^{1}$ Internal Medicine, University of loannina, Greece, Department of Internal Medicine, Medical School, University of loannina, loannina, Greece; ${ }^{2}$ Rheumatology Clinic, University of loannina, Ioannina, Greece, Department of Internal Medicine, Medical School, University of loannina, Ioannina, Greece

Background: Patients with UCTD cannot be definitely diagnosed with a well-characterized systemic rheumatic disease. These patients often exhibit one of several disease patterns, manifesting multiple nonspecific clinical or serologic abnormalities, sometimes of more than one defined rheumatic disorder.

Objectives: The aim of this study is to investigate lipid profile and atherosclerosis in UCTD patients.

Methods: This is a prospective, observational study which included 30 treatment-naïve UCTD patients. Thirty patients and 30 healthy matchedcontrols were compared for total cholesterol (TC), high-density lipoprotein cholesterol (HDL-c), low-density lipoprotein cholesterol (LDL-C) and triglycerides (TGs). Furthermore, in order to describe endothelial dysfunction and presence of atherosclerosis, we assessed intima-media thickness (IMT) of common carotid artery with the contribution of an experienced sonographer. We also measured Apolipoprotein A1 (ApoA1), Apolipoprotein $B(A p o B)$, Apolipoprotein $E(A p o E)$, Lipoprotein A (LpA), erythrocyte sedimentation rate (ESR), high-sensitivity C-reactive protein (HSCRP) and fibrinogen in the group of patients only.

Results: Thirty UCTD patients were studied. There were 11(36.7\%) men, $19(63.3 \%)$ women and $7(23.3 \%)$ smokers. The mean (SD) age was 54.4
(13.1) years and disease duration was 17.3(10.4) years. All reported Raynaud's phenomenon, 22(73.3\%) had esophagus disorders, $21(70 \%)$ had pulmonary fibrosis and $3(10 \%)$ pulmonary hypertension. Arthritis was present in a great majority of these patients (93\%). The immunological evaluation of the patients showed that $4(13.3 \%)$ had positive anticardiolipin antibodies and $11(36.7 \%)$ had scl-70 (+).

The comparison of IMT between patients and matched-controls revealed an increased IMT in UCTD patients $[0.82(0.32)$ vs $0.6 \quad(0.13) \mathrm{mm}$; $\mathrm{p}<0.001]$. There was also a significant difference in mean (SD) TC [204.4(43.03) in patients vs 238(41.4) in controls; $p$ value<0.004] with respective reduced levels of mean(SD) HDL in patients [50.6(9.5) vs 61.3 (13.3); $p$ value<0.002]. No statistically significant difference was found for LDL-c and TGs.

These patients had mean (SD) ApoA1 146.9(27.6), ApoB 94.9(25.6) ApoE 42.1(10.7), LpA 12.8 (15.9), HSCRP 7.5(13.5), ESR 28.9 (22.6 and fibrinogen 422.9(101.3).

Conclusion: IMT measurement confirmed that UCTD patients are prone to endothelial dysfunction and consequently to atherosclerosis. Treatmentnaive patients had reduced TC levels in combination with low levels of HDL-c reflecting high disease activity. Control of the disease and initiation of specific therapy may induce an improved lipid profile.

Disclosure of Interests: None declared

DOI: 10.1136/annrheumdis-2019-eular.6643

\section{FRI0324 DISEASE ACTIVITY INDICES IN SYSTEMIC SCLEROSIS- WHICH TO USE IN DAILY PRACTICE?}

Laura Groseanu $^{1,2}$, Sorana Petrescu ${ }^{1}$, Andra Balanescu ${ }^{1,2}$, Daniela Opris-

Belinski $^{1,2}$, Violeta Bojinca ${ }^{1,2}$, Florian Berghea ${ }^{1,2}$, loana Saulescu ${ }^{1,2}$,

Sanziana Daia-lliescu ${ }^{1,2}$, Diana Mazilu ${ }^{1,2}$, Andreea Borangiu ${ }^{1,2}$

Cosmin Constantinescu ${ }^{1,2}$, Maria Magdalena Negru ${ }^{1,2}$, Mihai Abobului ${ }^{1,2}$

Violeta Vlad', Ruxandra lonescu ${ }^{1,2} .{ }^{1}$ Carol Davila University of Medicine and

Pharmacy, Bucharest, Romania; ${ }^{2}$ Sf Maria Clinical Hospital, Bucharest, Romania

Background: Currently there is no fully validated index for assessing overall disease activity in patients with systemic sclerosis (SSc).

Objectives: To estimate the effect of disease activity as measured by 4 disease activity indices on the risk of subsequent organ damage in a EUSTAR center cohort.

Methods: Longitudinal observational study; European Systemic sclerosis study group disease activity index (EScSG DAI), revised EUSTAR disease activity index ( $r$-EUSTAR DAI), 12 point activity index proposed by Minier (12point DAI) were calculated for all patients; the CRISS (The Combined Response Index for Systemic Sclerosis) only for patients included after 2016. Student t-test/Mann-Whitney test, chi-square test were used to evaluate differences across subgroups; Pearson's bivariate correlation/Spearman's rank correlation coefficient to evaluate the association between variables. The predictive value of various variables for major organ involvement was assessed by Roc curves and univariate regression.

Results: 91 patients were selected,77 females (84,61\%), 51,65(13,20) years old at diagnosis, $49,45 \%$ diffuse subset.

Disease activity scores were all higher in male patients and in patients with diffuse cutaneous involvement, digital ulcers(DU), lung fibrosis, scleroderma renal crisis (SRC), arrythmias, muscle atrophy, gastric involvement, antitopoisomerase-1 positive, EscSG DAl correlated with forced vita capacity $(F V C)(r=0.73, p<0.001), \quad \operatorname{DLCO}(r=0.68, p<0.001), \quad D U(x 2=3.08$ $p=0.05)$, lung fibrosis $(x 2=10.90, p<0.0)$, systolic pulmonary arterial pressure (sPAP) $(r=0.54, p<0.001)$, muscle atrophy $(x 2=11,58, p=0.001)$, diffuse subset $(x 2=11,46, p=0.001)$.

R- EUSTAR DAI correlated with FVC $(r=0.6, p<0.001), \quad \operatorname{DLCO}(r=0,58$ $p<0.001)$, diffuse subset $(x 2=9,52, p<0.01)$, contractures $(x 2=11,23, p=0.001)$, muscle weakness $(x 2=6,61, p=0.01)$, muscle atrophy $(x 2=10,19, p<0.001)$ $\operatorname{SRC}(x 2=4,74, p=0.02)$ and $\operatorname{sPAP}(r=0.5, p<0.001)$.

12 point DAl correlated with $\mathrm{FVC}(r=0.57, \mathrm{p}<0.001), \quad \mathrm{DLCO}(\mathrm{r}=0.66, \mathrm{p}<0.001)$ and $\operatorname{sPAP}(r=0.42, \mathrm{p}<0.001)$.

EscSG predicted well lung fibrosis $(A \cup C=0.79, p<0.001), D U(A \cup C=0.66$, $\mathrm{p}<0.001)$, gastric involvement $(\mathrm{AUC}=0.73, \mathrm{p}<0.01)$ and $\mathrm{SRC}(\mathrm{AUC}=0.9$, $\mathrm{p}=0.01$ ). R-EUSTAR index also lung fibrosis ( $\mathrm{AUC}=0.76, \mathrm{p}<0.001$ ), $\quad \mathrm{DU}$ $(\mathrm{AUC}=0.82, \mathrm{p}<0.01)$ and $\mathrm{SRC}(\mathrm{AUC}=0.84, \mathrm{p}=0.04)$.

12point DAl was a good predictor for lung fibrosis $(A \cup C=0.74, p<0.01)$, DU $(A \cup C=0.78, p=0.05)$, gastric involvement $(A \cup C=0.76, p=0.01)$.

In the regression analysis, lung fibrosis(beta $=0.5,95 \% \mathrm{Cl}=1,21-2,58, \mathrm{p}<0.01$ ), muscle atrophy (beta $=1.49,95 \% \mathrm{Cl}=1.02-2.19, \mathrm{p}=0.03$ ) and rhythm and con duction disturbancies (beta $=1.98,95 \% \mathrm{Cl}=1.31-2.99, \mathrm{p}<0.001$ ) were independent predictors for disease activity evaluated by EScSG. For 12 EUSTAR DAI none of the evaluated parameters proved to independently contribuite to disease activity. For 12point DAl items independently 
contributing to disease activity were gastric involvement (beta=2.46,95\% $\mathrm{Cl}=1.19-5.09, \mathrm{p}=0.01$ ) and muscle atrophy (beta=2.05, $95 \% \mathrm{Cl}=1.03-4.08$, $\mathrm{p}=0.03)$.

The CRISS cohort included 35 patients, 32 females(91,42\%), 48.48(14.24) years old, $62.85 \%$ diffuse subset, medium disease duration 11.88(7.9) months. 8 patients were excluded due to new onset or worsening of lung fibrosis or SRC. None of the patients had a CRISS score with a probability of improvement>0.6.

Conclusion: We could not conclude that there is a gold standard to measure disease activity; for daily practice especially EscSG and rEUSTAR DAI quantify and predict major organ involvement. CRISS can be useful as an outcome measure for patients with short disease duration and closely monitored in clinical studies.

\section{REFERENCES:}

[1] K. Melsens, et al. Disease activity indices in systemic sclerosis: a systematic literature review Clin Exp Rheumatol 2016; 34 (Suppl. 100):S186S192.

Disclosure of Interests: Laura Groseanu: None declared, Sorana Petrescu: None declared, Andra Balanescu Speakers bureau: multiple, Daniela Opris-Belinski Grant/research support from: GLORIA, Speakers bureau: multiple, Violeta Bojinca Speakers bureau: multiple, Florian Berghea: None declared, Ioana Saulescu: None declared, Sanziana Daia-lliescu: None declared, Diana Mazilu Speakers bureau: Pfizer, UCB, Andreea Borangiu: None declared, Cosmin Constantinescu: None declared, Maria Magdalena Negru: None declared, Mihai Abobului: None declared, Violeta Vlad: None declared, Ruxandra lonescu: None declared DOI: 10.1136/annrheumdis-2019-eular.7527

\section{FRI0325 \\ IDENTIFYING SYSTEMIC SCLEROSIS PATIENTS AT RISK OF PROGRESSIVE LUNG FIBROSIS - A EUSTAR DATABASE ANALYSIS}

Anna-Maria Hoffmann-Vold ${ }^{1}$, Martina Gahlemann ${ }^{2}$, Nicole Graf ${ }^{3}$, Paolo Airò ${ }^{4}$, Lidia P. Ananyeva ${ }^{5}$, László Czirják ${ }^{6}$, Serena Guiducci ${ }^{7}$, Eric Hachulla ${ }^{8}$, LI Mengtao ${ }^{9}$, Carina Mihai $^{10}$, Gabriela Riemekasten ${ }^{11}$, Petros Sfikakis ${ }^{12}$, Gabriele Valentini ${ }^{13}$, Otylia Kowal-Bielecka ${ }^{14}$, Yannick Allanore ${ }^{15}$, Oliver Distler ${ }^{10}$. ${ }^{1}$ Oslo University Hospital, Department of Rheumatology, Oslo, Norway, ${ }^{2}$ Boehringer Ingelheim (Schweiz), GmbH, Basel, Switzerland; ${ }^{3}$ Graf Biostatistics, Winterthur, Switzerland; ${ }^{4}$ Spedali Civili di Brescia, UO Reumatologia e Immunologia Clinica, Brescia, Italy; ${ }^{5}$ VA Nasonova Institute of Rheumatology, Moscow, Russian Federation; ${ }^{6}$ University of Pécs, Department of Rheumatology and Immunology, Pécs, Hungary; ${ }^{7}$ University of Florence, Department of Clinical and Experimental Medicine, Section of Rheumatology, Florence, Italy; ${ }^{8} \mathrm{Hôpital} \mathrm{Claude} \mathrm{Huriez,}$ University of Lille, Department of Internal Medicine and Clinical Immunology, Lille, France; ${ }^{9}$ Peking Union Medical College Hospital, Department of Rheumatology, Beijing, China; ${ }^{10}$ University Hospital Zurich, Department of Rheumatology, Zurich, Switzerland; ${ }^{11}$ University of Medical Center Schleswig-Holstein, Department of Rheumatology and Clinical Immunology, Lübeck, Germany; ${ }^{12}$ National and Kapodistrian University of Athens Medical School, Joint Rheumatology Programme, Athens, Greece; ${ }^{13} / /$ Policlinico U.O. Reumatologia, Dipartimento di Medicina di Precisione, Napoli, Italy; ${ }^{14}$ Medical University of Bialystok, Department of Rheumatology and Internal Medicine, Bialystok, Poland; ${ }^{15}$ Descartes University, APHP, Cochin Hospital, Department of Rheumatology A, Paris, France

Background: Early identification of patients with systemic sclerosis-associated interstitial lung disease (SSc-ILD) at risk of progression could help tailor management and aid cohort enrichment in clinical trials to improve outcome.

Objectives: To assess the frequency of progressive SSc-ILD in the total ILD cohort and in subgroups enriched by risk factors in the EUSTAR database.

Methods: Patients from the EUSTAR database registered after $2010, \geq 18$ yrs old, fulfilling SSc classification criteria, with serial lung function and HRCT assessments were eligible. The following risk factors for progressive SSc-ILD available in the EUSTAR database were chosen as enrichment criteria: low forced vital capacity (FVC) and diffusing capacity for carbon monoxide ( $\left(\mathrm{L}_{\mathrm{CO}}\right)$, diffuse cutaneous SSc, anti-topoisomerase I antibody (ATA), short disease duration, older age, male sex, increased Creactive protein, and presence of respiratory symptoms and reflux disease. Eligible patients with progressive ILD were assessed in the cohort and in subgroups enriched by the risk factors. Progressive SSc-ILD was assessed as absolute changes in\%predicted and defined as: significant progressive (FVC decline $>10 \%$, or FVC decline $5-10 \%$ and $\mathrm{DL}_{\mathrm{CO}}$ decline $\geq 15 \%$ ), moderate progressive (FVC decline $5-10 \%$ ) or stable ( $<5 \%$ FVC change in either direction). The follow-up period was defined as time from baseline to last available lung function test.

Results: 6004 patients fulfilled the main entry criteria; of these, 1822 $(30.3 \%)$ had ILD. At baseline, mean age was $57 \mathrm{yrs}, 17.4 \%$ were male, $48.2 \%$ had diffuse SSc, $53.5 \%$ were ATA-positive, mean baseline FVC $86 \%$ and $\mathrm{DL}_{\mathrm{CO}} 59 \%$, mean disease duration $9.8 \mathrm{yrs}$, and follow-up was $2.5 \mathrm{yrs}$. In the total ILD cohort (30\% eligible patients), $21 \%$ showed progressive ILD. Enriching with single risk factors reduced the number of eligible patients down to $6 \%$, while the frequency of progressive ILD stayed stable (Figure). Combinations of risk factors did not result in increasing numbers of progressive ILD patients, but in further decreasing numbers of eligible patients.

Conclusion: There is still an unmet need to identify SSc-ILD patients at risk of progression with efficient risk factors. For clinical trials, it is a challenge to balance feasibility of recruitment and enrichment.

Acknowledgement: Funding: Boehringer Ingelheim (Schweiz) $\mathrm{GmbH}$, Switzerland

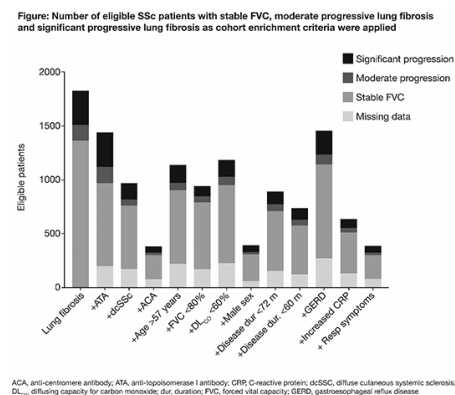

Disclosure of Interests: Anna-Maria Hoffmann-Vold Grant/research support from: Received research funding or other remuneration from Boehringer Ingelheim, GSK, and Actelion, Consultant for: Received consulting fees or other remuneration from Boehringer Ingelheim, GSK, and Actelion, Speakers bureau: Actelion and Boehringer Ingelheim, Martina Gahlemann Employee of: Employee of Boehringer Ingelheim

Nicole Graf Grant/research support from: Received consulting fees or other remuneration from Astellas and Biotronik, Paolo Airò: None declared, Lidia P. Ananyeva: None declared, László Czirják: None declared, Serena Guiducci: None declared, Eric Hachulla Consultant for: Received consulting fees or other remuneration from Actelion, GSK, Pfizer, and Bayer, Mengtao Li: None declared, Carina Mihai Consultant for: Received consulting fees or other remuneration from Actelion, Gen eva, Roche, and Rofarm, Consultant for: F. Hoffmann-La Roche, Actelion, Geneva Romfarm, Gabriela Riemekasten Consultant for: Chugai, F. Hoffmann-La Roche, Speakers bureau: Chugai, F. Hoffmann-La Roche, Petros Sfikakis: None declared, Gabriele Valentini Grant/research support from: Received research funding and other remuneration from AbbVie, BMS, Lilly, Pfizer, and Sanofi, Consultant for: Received consulting fees and other remuneration from AbbVie, BMS, Lilly, Pfizer, and Sanofi, Otylia Kowal-Bielecka Consultant for: Received consulting fees or other remuneration from Bayer, Boehringer Ingelheim, Inventiva, Medac, Novartis, and Roche, Yannick Allanore Grant/research support from: Inventiva, F Hoffman La-Roche, Sanofi, BMS, Pfizer, Consultant for: Actelion, Bayer, BMS, Boehringer, Roche, Sanofi, Oliver Distler Grant/research support from: Prof. Distler received research funding from Actelion, Bayer, Boehringer Ingelheim and Mitsubishi Tanabe to investigate potential treatments of scleroderma and its complications, Consultant for: Prof. Distler has/had consultancy relationship within the last 3 years with Actelion, AnaMar, Bayer, Boehringer Ingelheim, ChemomAb, espeRare foundation, Genen tech/Roche, GSK, Inventiva, Italfarmaco, iQvia, Lilly, medac, Medlmmune, Mitsubishi Tanabe Pharma, Pharmacyclics, Novartis, Pfizer, Sanofi, Serodapharm and UCB in the area of potential treatments of scleroderma and its complications. In addition, he had/has consultancy relationship within the last 3 years with A. Menarini, Amgen, Abbvie, GSK, Mepha, MSD, Pfizer and UCB in the field of arthritides and related disorders DOI: 10.1136/annrheumdis-2019-eular.2574 